\title{
Circuit
}

Musiques contemporaines

\section{Québec : traces sonores du printemps 2012}

" et tout ce qu'on entendait, c'était la clameur populaire, au

loin »

\section{Symon Henry et Emanuelle Majeau-Bettez}

Volume 28, numéro 3, 2018

URI : https://id.erudit.org/iderudit/1055197ar

DOI : https://doi.org/10.7202/1055197ar

Aller au sommaire du numéro

Éditeur(s)

Circuit, musiques contemporaines

ISSN

1183-1693 (imprimé)

1488-9692 (numérique)

Découvrir la revue

Citer ce document

Henry, S. \& Majeau-Bettez, E. (2018). Québec : traces sonores du printemps 2012 : « et tout ce qu'on entendait, c'était la clameur populaire, au loin ». Circuit, 28(3), 87-88. https://doi.org/10.7202/1055197ar d'utilisation que vous pouvez consulter en ligne.

https://apropos.erudit.org/fr/usagers/politique-dutilisation/ 


\section{EXCLUSIVITÉ WEB}

\section{Québec : traces sonores du printemps 2012}

«et tout ce qu'on entendait, c'était la clameur populaire, au loin ${ }^{1} »$

Une enquête en ligne de Symon Henry

et Emanuelle Majeau-Bettez

Enquête disponible en ligne sur la plateforme Hypothèses:

https:/quebec2o12.hypotheses.org

ainsi que sur le site internet de la revue Circuit:

https://revuecircuit.ca/web

Ce carnet retrace certains des sons, des chansons, des bruits et des clameurs que les manifestations étudiantes et le mouvement social du printemps 2012 ont laissés derrière eux au Québec. Classées par temporalités - le temps des actions, des casseroles, des chansons, etc. - plutôt que par genres musicaux, les traces sonores recensées dans cette enquête invitent les lecteur.esauditeur.es à replonger au temps de leur émergence. Ainsi, six ans plus tard, on réécoute, par exemple, le 25 mai 2012 à 21 h, à l'intersection des rues Villeray et Saint-Hubert à Montréal, des personnes âgées qui commentent le passage d'une manifestation étudiante; on réentend le 22 avril 2012 où, pour le Jour de la Terre, des milliers de cloches ont sonné partout au Québec. On y redécouvre les chansons composées en lien avec ces événements par des artistes connu.es de la pop ou du hip-hop, mais aussi d'autres, moins connu-es, retracé.es dans les méandres de YouTube ou de Bandcamp. Ariane Moffatt, DJ-Horg, Yann Perreau, Godspeed You! Black Emperor et Jon Lajoie se retrouvent ainsi sous le même index qu'un groupe d'étudiantes du Cégep de Drummondville, qu'un certain Jasmin Lafortune, alias PoPO, ou que 2 Bonnes Patates.

Un printemps tout en contrastes où la ballade romantique «Dans les Yeux de Léo» de DouceRebelle aura été mise en ligne la veille de la chanson punk «Osti d'Frisé» des bands Shyshit, Unexpect et Dark Shit of Death. Un
1. Régine Debrosse, Montréal, souvenir reçu sur le mur Facebook de Symon Henry, 2 décembre 2017. 
2. Vous aimeriez partager une description d'un souvenir sonore, nous signaler l'existence d'une trace sonore que vous possédez ou d'une œuvre musicale que vous avez composée? Écrivez-nous et nous serons heureux de mettre à jour notre enquête: info@revuecircuit.ca. printemps tout en résonances, aussi, puisque de différents regroupements et actions sont nés des projets artistiques pérennes aussi divers que l'étiquette Acte, le band post-punk Ought ou encore l'Orchestre symphonique de l'Agora.

Chorales, orchestres, plusieurs pièces de musique contemporaine et concerts marquants y sont répertoriés, souvent grâce à des musicien·nes, compositeur.es ou témoins qui ont partagé avec nous leurs souvenirs et autres documents pertinents. Entre deux chansons plutôt ludiques, on y retrouve également certains documents témoignant du cas du groupe Mise en demeure, ou encore des chansons "Charest dans un coffre de char» et «!!! GARDE TA MAIN SUR LA BRIQUE!!! (L'Internet feat. le SPVM)», controversés de par la violence de leurs propos. Mu.es par le devoir de mémoire, nous avons répertorié un large éventail de sources sonores primaires, avant tout dans le but qu'il serve d'outils de travail pour des projets de création ou de recherche futurs. Quelque 150 sources ont été recueillies jusqu'à maintenant, et nous espérons que ce projet de collecte de données continuera de croître au fil des ans².

\section{Note}

Emanuelle Majeau-Bettez était étudiante au baccalauréat en musicologie et piano à l'Université McGill lors du printemps 2012. Symon Henry, pour sa part, était alors étudiant à la maîtrise (DESM II) en composition et analyse musicale au Conservatoire de musique de Montréal, où il était représentant des compositeures à l'Association étudiante et membre de son comité de grève. Nous avons tenté d'approcher la recension des traces sonores de ce moment important de l'histoire sociale québécoise avec le plus d'objectivité possible, en nous basant sur nos réseaux (artistiques, scolaires et sociaux) et ressources propres, tout en reconnaissant les limites de cette démarche. 